\title{
Revisiting the Use of Language Learning Strategies by University Freshmen in Taiwan
}

\author{
Jia-Ying Lee ${ }^{1}$ \\ ${ }^{1}$ English Department, Tamkang University, Taiwan \\ Correspondence: 51 Yingzhuan Road, Danshui District, New Taipei City 251, Taiwan. E-mail: \\ jylee@mail.tku.edu.tw
}

Received: May 3, 2019 Accepted: June 10, 2019 Online Published: July 18, 2019

doi:10.5539/ijel.v9n5p1 URL: https://doi.org/10.5539/ijel.v9n5p1

\begin{abstract}
This article reports a large-scale survey on the use of language learning strategies by first-year college students in Taiwan, with the aim of describing what language learning strategies they reported using and what strategic patterns were formed. A total of 199 non-English majors responded to a survey designed by Oxford (1990), namely, the Strategies Inventory for Language Learning (SILL) (Version 7.0). The results show that today's language learners self-reported using the following SILL strategies in the following order of frequency: compensation strategies, metacognitive strategies, social strategies, memory strategies, cognitive strategies, and affective strategies. In addition, the results also demonstrate that three SILL categories used today were used differently in the past: affective strategies, metacognitive strategies, and compensation strategies. Moreover, it was also found that males and females these days had slightly different strategic patterns from one another in learning English and also used slightly different ones in the past.
\end{abstract}

Keywords: learning strategies, language learning strategies, English as a foreign language

\section{Introduction}

Language learning strategies (LLS) have been a popular research topic in the field of foreign language learning over the past four decades, roughly speaking (Anam \& Stracke, 2016; Cohen \& Griffiths, 2015; Rose, Briggs, Boggs, Sergio, \& Ivanova-Slavianskaia, 2018). Two significant factors to account for this continual popularity are the empirical effects of LLS, which are meaningfully associated with language proficiency (Rao, 2016; Cáceres-Lorenzo, 2015), and their learning outcomes (cf., Green \& Oxford, 1995; Hsiao \& Oxford, 2002; Khodadad \& Kaur, 2019; Mizumoto \& Takeuchi, 2009). Specifically, advanced language learners tend to employ LLS more frequently and in more varied contexts than do low achievers (Ehrman \& Oxford, 1990; Green \& Oxford, 1995; Lee, 2018; Magogwe \& Oliver, 2007). Learning to use specific groups of LLS also effectively leads to enhanced performance in different linguistic areas, such as reading (Lee, in press), vocabulary (Mizumoto \& Takeuchi, 2009), speaking (Cohen, Weaver, \& Li, 1998), listening (Ngo, 2019), and writing (Nguyen \& Gu, 2013; Rao, 2007). While the empirical evidence supports the view that LLS improve language performance and proficiency, their ultimate goal (cf., Oxford, 2017), the underlying features of LLS described by Oxford (1990) and endorsed by scholars (e.g., Khodadad \& Kaur, 2019; Yang, 2017) explain their efficacy: LLS are "specific actions taken by the learner to make learning easier, faster, more enjoyable, more self-directed, more effective and more transferable to new situations" (Oxford, 1990, p. 8).

The evidence from the great number of experimental studies over the past few decades confirms the positive relationship between the use of LLS and language proficiency. Nevertheless, an interesting question calling for an empirical revisit to further our understanding of LLS is whether or not today's learners use LLS differently from those in the past. Revisiting this issue is important in light of the drastic changes of context for today's language learners. First, most learners nowadays were born into the present digital era where aids to language learning (e.g., online materials and video or audio clips) are easily and freely accessible from the Internet (cf., Tan, Ng, \& Saw, 2010). Advanced technologies and developments in media (such as smartphones and YouTube) are transforming the way that individuals learn and interact with others (Meyers, Erickson, \& Small, 2013; Haythornthwaite, Andrews, Fransman, \& Meyers, 2016). Meanwhile, the fact that the world is becoming flatter than ever before (cf., Freidman, 2005) has also brought more incentives for modern language learners (Chang, 2015), in terms of, for example, opportunities to interact with speakers of different languages, being taught by 
native speakers of the target language, or accessing foreign goods and materials that have labels or manuals with explanations in different languages. The changes make it tempting to assume that being exposed to such a new learning environment may in turn have changed the ways in which LLS are used by today's students to cope with learning tasks or goals. Finally, communicative language teaching all over the world has been more warmly welcomed than before (cf., Rahman \& Pandian, 2018). This may somewhat affect the teaching and learning of a language in many contexts, thus resulting in different learner models from those in the past when the traditional deductive approach was dominant.

In light of the changes described, this study aims to carry out a large-scale survey on the use of LLS by today's language learners to find whether they have adopted new strategic patterns. A particularly suitable context for this survey was higher education in Taiwan, where English is mostly taught and learned as a foreign language (EFL). Over the past years, Taiwanese society has experienced the changes described above, including the popularity of the Internet and affordable new technologies and applications (e.g., tablets, smartphones). Additionally, the communicative approach was introduced to Taiwan's English educational settings around 15 years ago (i.e., 2004). It succeeded English classes that mostly relied on deductive, teacher-centered lecturing, and one-way communicative approaches (i.e., from teachers to students) (cf., Lee, 2013; Lin, 2016; Lin \& Lee, 2017). Given this background, it would seem to be particular rewarding to look at the current strategic patterns of language learning among Taiwanese university students and compare them with past patterns. Accordingly, the research question formulated for this study is What language learning strategies do today's EFL students in Taiwan use? To help answer this question, a few preliminary questions should first be addressed.

1) What are the general patterns of strategy use?

2) What strategies are used more often than others?

3) Are there differences between the strategies used by males and by females?

\section{The Study}

\subsection{The Participants}

The participants chosen to represent today's participants were first-year non-English-majors from a comprehensive university in Taiwan. A total of 249 freshmen responded to the survey (see the next section), producing in the end 199 valid questionnaires ( 77 from males, 122 from females), an effective response rate of $79.91 \%$. Their majors were physics, Japanese, Spanish, industrial economics, accounting, and statistics. Most of the sample were aged either 18 or 19 , an age-range which should adequately represent today's language learners. They were born in Taiwan around 2000 and would have started elementary school in or near 2006, after the communicative approach to language teaching had been launched in Taiwan. It was also after the Internet and other advanced technologies had become affordable to most members of the public and had been widely integrated into most educational settings.

\subsection{Instrument}

The Strategies Inventory for Language Learning (SILL) (Version 7.0) (Oxford, 1990) was chosen for this study. The SILL, designed to use a five-point Likert scale, contains 50 strategy items; a score of one indicates never true and of five, always true. It was chosen for this study for two major reasons.

First, the SILL is one of the indices that cover the most comprehensive dimensions of the strategies for learning a language (Hsiao \& Oxford, 2002). It covers six categories: using memory (nine items), being cognitive (14 items), being compensatory (six items), being metacognitive (nine items), being affective (six items), and being social (six items). Memory strategies are the ways in which learners remember new linguistic input; cognitive strategies relate to the interaction with the material to be learned; compensatory strategies are techniques that enable learners to make up for insufficient knowledge; metacognitive strategies are the ways in which learners manage their learning process; affective strategies are associated with learners' emotional control; and social strategies relate to learners' ways of learning with others. The inclusiveness of Oxford's SILL seems to represent adequately all the strategic patterns of language learners.

Second, the SILL is persistently reliable and valid in a range of contexts (Oxford \& Burry-Stock, 1995; Papadopoulou, Kantaridou, Platsidou, \& Gavriilidou, 2018), which has helped it maintain long-lasting popularity in language experimental sites (e.g., Gunning \& Oxford, 2014; Saks \& Leijen, 2018; Rose et al., 2018; Shin \& So, 2018; Wright, Ahn, \& Lee, 2018; Yang, 2018). These qualities of SILL are likely to best produce effective accounts of respondents' strategic behaviors in language learning.

It should be noted that, because the levels of English proficiency of the participants involved in this study might 
have prevented them from responding correctly to the English version of the SILL, Yang's (1992) Chinese version of it was adopted in this study instead. Yang's version was a faithful translation of Oxford's SILL and showed high reliability and validity in tests (Yang, 1992, 1999). It has also been widely acknowledged, used, and discussed in Chinese educational contexts (e.g., Lan \& Oxford, 2003; Yang, 2007).

\subsection{Data Analysis}

Both descriptive and inferential statistics were used to analyze the data (learners' scores in the SILL), with the aim of comprehensively revealing students' strategic patterns. Specifically, the order of frequency of use of the SILL categories was first determined. Then the individual SILL strategies were ranked according to the frequency of their use. Next, paired samples t-tests were applied to determine whether the genders had shown any significant variation of the mean in their strategy use.

\section{Results}

\subsection{Overall Results}

Table 1 presents the descriptive statistics of the six categories described in the SILL items, which are listed from the most frequently used category to the least. In the order of frequency, compensation strategies are the most frequently used category $(\mathrm{M}=3.46, \mathrm{SD}=.70)$; metacognitive strategies second $(\mathrm{M}=3.26$; $\mathrm{SD}=.76)$; social strategies third $(\mathrm{M}=3.25, \mathrm{SD}=.74)$; memory strategies fourth $(\mathrm{M}=3.23, \mathrm{SD}=.64)$; cognitive strategies fifth $(\mathrm{M}=3.16, \mathrm{SD}=.74)$; and affective strategies sixth $(\mathrm{M}=3.00, \mathrm{SD}=.79)$. In addition, all the categories were shown to have a mean of at least 3.00. Taken together, these results suggest that generally the university students nowadays used LLS of different types to help them to learn English, with a preference for certain categories of strategy over others.

Table 1. Overall results of the SILL categories $(N=199)$

\begin{tabular}{lllllll}
\hline Rank order of use by frequency & Category & Item & Min. & Max. & Mean & $S D$ \\
\hline 1 & Compensation & $24-29$ & 1.50 & 5.00 & 3.46 & 0.70 \\
2 & Metacognitive & $30-38$ & 1.33 & 5.00 & 3.26 & 0.76 \\
3 & Social & $45-50$ & 1.00 & 5.00 & 3.25 & 0.74 \\
4 & Memory & $1-9$ & 1.33 & 5.00 & 3.23 & 0.64 \\
5 & Cognitive & $10-23$ & 1.21 & 5.00 & 3.16 & 0.74 \\
6 & Affective & $39-44$ & 1.00 & 5.00 & 3.00 & 0.79 \\
\hline
\end{tabular}

Table 2 presents the descriptive statistics of all the SILL items, ranked by the frequency with which they were used. Specifically, the top $1 / 3$ of strategies (ranking 1-17) cover items across almost all the SILL categories except for that of affective, of which only Strategy $42(\mathrm{M}=3.44, \mathrm{SD}=1.12)$ entered. The mean scores of the top $1 / 3$ of strategies were all above 3.36 (inclusive), which suggests that the participants often used them to learn English. Additionally, within the top $1 / 3$ of strategies, the three most frequently used were Strategy $24(M=3.95$, $\mathrm{SD}=.84)$, Strategy $29(\mathrm{M}=3.93, \mathrm{SD}=.92)$, and Strategy $45(\mathrm{M}=3.83, \mathrm{SD}=.88)$. This may suggest that the participants collectively deem them the most useful or effective ones for learning English.

The bottom 1/3 of strategies (Ranking 34-50) also included items from different SILL categories, with the most frequently used among them (i.e., ranking 34: Strategy 7) having a mean score of 3.09, and the least used one (ranking 50: Strategy 43) a mean score of only 2.10. This suggests that in general the participants used these strategies less frequently in learning English. This applies even to with the three strategies that were used least: Strategy $16(\mathrm{M}=2.59, \mathrm{SD}=1.11)$, Strategy $34(\mathrm{M}=2.58, \mathrm{SD}=1.03)$, and Strategy $43(\mathrm{M}=2.10, \mathrm{SD}=1.13)$. 
Table 2. Ranking of individual strategies: overall results $(N=199)$

\begin{tabular}{|c|c|c|c|c|c|}
\hline Ranking & Strategy No. (Category*) & Min. & Max. & Mean & SD \\
\hline 1 & $24(\mathrm{COM})$ & 1.00 & 5.00 & 3.95 & 0.84 \\
\hline 2 & $29(\mathrm{COM})$ & 1.00 & 5.00 & 3.93 & 0.92 \\
\hline 3 & 45 (SOC) & 1.00 & 5.00 & 3.83 & 0.88 \\
\hline 4 & 32 (MET) & 1.00 & 5.00 & 3.78 & 1.02 \\
\hline 5 & 33 (MET) & 1.00 & 5.00 & 3.76 & 0.99 \\
\hline 6 & 1 (MEM) & 2.00 & 5.00 & 3.62 & 0.87 \\
\hline 7 & 4 (MEM) & 1.00 & 5.00 & 3.60 & 0.94 \\
\hline 8 & $21(\mathrm{COG})$ & 1.00 & 5.00 & 3.59 & 1.04 \\
\hline 9 & $10(\mathrm{COG})$ & 1.00 & 5.00 & 3.56 & 1.06 \\
\hline 10 & $27(\mathrm{COM})$ & 1.00 & 5.00 & 3.56 & 1.02 \\
\hline 11 & 5 (MEM) & 1.00 & 5.00 & 3.55 & 1.07 \\
\hline 12 & 31 (MET) & 1.00 & 5.00 & 3.51 & 0.90 \\
\hline 13 & $15(\mathrm{COG})$ & 1.00 & 5.00 & 3.48 & 1.18 \\
\hline 14 & 30 (MET) & 1.00 & 5.00 & 3.47 & 0.96 \\
\hline 15 & $12(\mathrm{COG})$ & 1.00 & 5.00 & 3.46 & 1.06 \\
\hline 16 & $42(\mathrm{AFF})$ & 1.00 & 5.00 & 3.44 & 1.12 \\
\hline 17 & $25(\mathrm{COM})$ & 1.00 & 5.00 & 3.36 & 1.12 \\
\hline 18 & 39 (AFF) & 1.00 & 5.00 & 3.34 & 1.00 \\
\hline 19 & 38 (MET) & 1.00 & 5.00 & 3.32 & 0.95 \\
\hline 20 & 48 (SOC) & 1.00 & 5.00 & 3.32 & 1.15 \\
\hline 21 & 3 (MEM) & 1.00 & 5.00 & 3.31 & 1.08 \\
\hline 22 & $22(\mathrm{COG})$ & 1.00 & 5.00 & 3.31 & 1.02 \\
\hline 23 & $13(\mathrm{COG})$ & 1.00 & 5.00 & 3.27 & 1.04 \\
\hline 24 & $19(\mathrm{COG})$ & 1.00 & 5.00 & 3.28 & 1.06 \\
\hline 25 & 9 (MEM) & 1.00 & 5.00 & 3.24 & 1.23 \\
\hline 26 & 40 (AFF) & 1.00 & 5.00 & 3.23 & 1.07 \\
\hline 27 & 50 (SOC) & 1.46 & 5.00 & 3.22 & 0.62 \\
\hline 28 & 41 (AFF) & 1.00 & 5.00 & 3.18 & 1.14 \\
\hline 29 & $11(\mathrm{COG})$ & 1.00 & 5.00 & 3.17 & 1.20 \\
\hline 30 & $20(\mathrm{COG})$ & 1.00 & 5.00 & 3.16 & 0.97 \\
\hline 31 & 46 (SOC) & 1.00 & 5.00 & 3.15 & 1.07 \\
\hline 32 & 8 (MEM) & 1.00 & 5.00 & 3.12 & 1.07 \\
\hline 33 & 37 (MET) & 1.00 & 5.00 & 3.10 & 1.02 \\
\hline 34 & 7 (MEM) & 1.00 & 5.00 & 3.09 & 1.12 \\
\hline 35 & 36 (MET) & 1.00 & 5.00 & 3.08 & 1.01 \\
\hline 36 & $14(\mathrm{COG})$ & 1.00 & 5.00 & 3.08 & 1.12 \\
\hline 37 & $28(\mathrm{COM})$ & 1.00 & 5.00 & 3.06 & 1.19 \\
\hline 38 & 49 (SOC) & 1.00 & 5.00 & 3.04 & 1.02 \\
\hline 39 & $23(\mathrm{COG})$ & 1.00 & 5.00 & 2.93 & 1.08 \\
\hline 40 & 2 (MEM) & 1.00 & 5.00 & 2.90 & 1.03 \\
\hline 41 & $26(\mathrm{COM})$ & 1.00 & 5.00 & 2.88 & 1.24 \\
\hline 42 & 35 (MET) & 1.00 & 5.00 & 2.77 & 1.12 \\
\hline 43 & 44 (AFF) & 1.00 & 5.00 & 2.74 & 1.17 \\
\hline 44 & $18(\mathrm{COG})$ & 1.00 & 5.00 & 2.72 & 1.16 \\
\hline 45 & 47 (SOC) & 1.00 & 5.00 & 2.69 & 1.08 \\
\hline 46 & 17 (COG) & 1.00 & 5.00 & 2.64 & 1.14 \\
\hline 47 & 6 (MEM) & 1.00 & 5.00 & 2.62 & 1.19 \\
\hline 48 & $16(\mathrm{COG})$ & 1.00 & 5.00 & 2.59 & 1.11 \\
\hline 49 & 34 (MET) & 1.00 & 5.00 & 2.58 & 1.03 \\
\hline 50 & 43 (AFF) & 1.00 & 5.00 & 2.10 & 1.13 \\
\hline
\end{tabular}

Note. ${ }^{*} \mathrm{COM}=$ compensation; $\mathrm{MET}=$ metacognitive; $\mathrm{SOC}=$ social; $\mathrm{MEM}=$ memory $\mathrm{COG}=$ cognitive; $\mathrm{AFF}=$ affective.

\subsection{Gender Differences}

Tables 3 and 4 present the descriptive statistics of the six categories described in the SILL items arranged by gender. The categories are shown from the most frequently used to the least. First, in line with the overall strategic patterns described above, in learning English, both genders used compensation strategies most frequently $\left(\mathrm{M}_{\text {male }}=3.51, \mathrm{SD}=.77 ; \mathrm{M}_{\text {female }}=3.43, \mathrm{SD}=.66\right)$ and affective strategies least $\left(\mathrm{M}_{\text {male }}=2.89, \mathrm{SD}=.96\right.$; 
$\left.\mathrm{M}_{\text {female }}=3.07, \mathrm{SD}=.66\right)$. However, totally different strategic patterns from the two genders were found with the other categories. In order, males preferred social $(\mathrm{M}=3.27, \mathrm{SD}=.86)$, metacognitive $(\mathrm{M}=3.22, \mathrm{SD}=.85)$, cognitive $(\mathrm{M}=3.21, \mathrm{SD}=.84)$, and memory $(\mathrm{M}=3.19, \mathrm{SD}=.80)$. Females liked metacognitive $(\mathrm{M}=3.29, \mathrm{SD}$ $=.69)$, memory $(\mathrm{M}=3.25, \mathrm{SD}=.51)$, social $(\mathrm{M}=3.23, \mathrm{SD}=.66)$, and cognitive $(\mathrm{M}=3.13, \mathrm{SD}=.67)$. This suggests that students of different genders mostly had different strategic patterns in learning English.

Table 3. Strategic patterns of the SILL categories by males $(N=77)$

\begin{tabular}{lllllll}
\hline Ranking of frequency & Category & Strategy & Min. & Max. & Mean & $S D$ \\
\hline 1 & Compensation & $24-29$ & 1.50 & 5.00 & 3.51 & 0.77 \\
2 & Social & $45-50$ & 1.00 & 5.00 & 3.27 & 0.86 \\
3 & Metacognitive & $30-38$ & 1.33 & 5.00 & 3.22 & 0.85 \\
4 & Cognitive & $10-23$ & 1.21 & 5.00 & 3.21 & 0.84 \\
5 & Memory & $1-9$ & 1.33 & 5.00 & 3.19 & 0.80 \\
6 & Affective & $39-44$ & 1.00 & 5.00 & 2.89 & 0.96 \\
\hline
\end{tabular}

Table 4. Strategic patterns of the SILL by females $(N=122)$

\begin{tabular}{lllllll}
\hline Ranking of frequency & Category & Strategy & Min. & Max. & Mean & $S D$ \\
\hline 1 & Compensation & $24-29$ & 1.83 & 5.00 & 3.43 & 0.66 \\
2 & Metacognitive & $30-38$ & 1.33 & 5.00 & 3.29 & 0.69 \\
3 & Memory & $1-9$ & 2.11 & 5.00 & 3.25 & 0.51 \\
4 & Social & $45-50$ & 1.67 & 5.00 & 3.23 & 0.66 \\
5 & Cognitive & $10-23$ & 1.36 & 5.00 & 3.13 & 0.67 \\
6 & Affective & $39-44$ & 1.67 & 5.00 & 3.07 & 0.66 \\
\hline
\end{tabular}

Despite the different strategic patterns between genders, when the frequency of use of each SILL category was compared between genders, no significant $t$ values were found in any of the six categories (compensation: $t(197)$ $=.84, \mathrm{p}=.404$; metacognitive: $\mathrm{t}(197)=-.64, \mathrm{p}=.522$; social: $\mathrm{t}(197)=.37, \mathrm{p}=.712$; memory: $\mathrm{t}(197)=-.72, \mathrm{p}$ $=.472$; cognitive: $\mathrm{t}(197)=.80, \mathrm{p}=.424$; affective: $\mathrm{t}(197)=-1.56, \mathrm{p}=.121)$. This suggests that while males and females do prefer different strategic patterns, the differences in terms of the frequency of use of the various SILL categories were not statistically meaningful.

Table 5. Results of the paired samples t-tests on strategy use by genders

\begin{tabular}{llllllll}
\hline Category & Gender & $\mathrm{N}$ & Mean difference & $S E$ & $d f$ & $t$ & $p$ \\
\hline Compensation & Male & 77 & .086 & .10 & 197 & .84 & .404 \\
& Female & 122 & & & & & \\
Metacognitive & Male & 77 & -.07 & .11 & 197 & -.64 & .522 \\
& Female & 122 & & & & & \\
Social & Male & 77 & .04 & .11 & 197 & .37 & .712 \\
& Female & 122 & & & & & \\
Memory & Male & 77 & -.07 & .09 & 197 & -.72 & .472 \\
& Female & 122 & & & & & \\
Cognitive & Male & 77 & .09 & .11 & 197 & .80 & .424 \\
& Female & 122 & & & & & \\
Affective & Male & 77 & -.18 & .11 & 197 & -1.56 & .121 \\
& Female & 122 & & & & & \\
\hline
\end{tabular}

Table 6 reveals in more detail the effects of gender differences in terms of the ranking of individual strategies by frequency. First, both genders similarly gave positive endorsement to certain strategies in the top ranking (e.g., Strategies 24, 29, 45, 32, and 33) and similarly less favorable strategies in the bottom ranking (e.g., Strategies 43, $16,17,6,34,47$, and 35). However, as regards individual strategies, males and females prioritized different strategies. For example, great gaps in ranking between the genders by at least 10 places were found with Strategies $8,9,10,13,15,41$, and 48 . Medium-sized gaps in ranking by 5 to 9 places were found with Strategies $5,21,22,31,38,39$, and 42 . 
Table 6. Ranking of individual strategies by gender $\left(N_{\text {male }}=77, N_{\text {female }}=122\right)$

\begin{tabular}{|c|c|c|c|c|c|c|c|c|c|c|}
\hline \multirow[t]{2}{*}{ Ranking } & \multicolumn{2}{|c|}{ Strategy No. } & \multicolumn{2}{|l|}{ Min. } & \multicolumn{2}{|l|}{ Max. } & \multicolumn{2}{|c|}{ Mean } & \multicolumn{2}{|l|}{$S D$} \\
\hline & $\mathrm{M}$ & $\mathrm{F}$ & $\mathrm{M}$ & $\mathrm{F}$ & $\mathrm{M}$ & $\mathrm{F}$ & $\mathrm{M}$ & $\mathrm{F}$ & $\mathrm{M}$ & $\mathrm{F}$ \\
\hline 1 & 24 & 29 & 1.00 & 2.00 & 5.00 & 5.00 & 4.03 & 3.92 & 0.92 & 0.86 \\
\hline 2 & 29 & 24 & 1.00 & 2.00 & 5.00 & 5.00 & 3.96 & 3.91 & 1.01 & 0.79 \\
\hline 3 & 45 & 45 & 1.00 & 2.00 & 5.00 & 5.00 & 3.83 & 3.83 & 1.04 & 0.77 \\
\hline 4 & 32 & 33 & 1.00 & 1.00 & 5.00 & 5.00 & 3.77 & 3.80 & 1.09 & 0.93 \\
\hline 5 & 21 & 32 & 1.00 & 1.00 & 5.00 & 5.00 & 3.74 & 3.79 & 1.15 & 0.98 \\
\hline 6 & 33 & 10 & 1.00 & 1.00 & 5.00 & 5.00 & 3.70 & 3.63 & 1.09 & 0.98 \\
\hline 7 & 1 & 5 & 2.00 & 1.00 & 5.00 & 5.00 & 3.68 & 3.61 & 1.03 & 1.02 \\
\hline 8 & 27 & 1 & 2.00 & 2.00 & 5.00 & 5.00 & 3.66 & 3.58 & 1.05 & 0.76 \\
\hline 9 & 15 & 4 & 1.00 & 1.00 & 5.00 & 5.00 & 3.66 & 3.58 & 1.21 & 0.93 \\
\hline 10 & 4 & 31 & 1.00 & 1.00 & 5.00 & 5.00 & 3.64 & 3.56 & 0.96 & 0.84 \\
\hline 11 & 50 & 42 & 1.00 & 1.00 & 5.00 & 5.00 & 3.52 & 3.53 & 1.22 & 1.01 \\
\hline 12 & 48 & 27 & 1.00 & 1.00 & 5.00 & 5.00 & 3.51 & 3.50 & 1.25 & 1.00 \\
\hline 13 & 5 & 21 & 1.00 & 1.00 & 5.00 & 5.00 & 3.47 & 3.49 & 1.14 & 0.96 \\
\hline 14 & 30 & 30 & 1.00 & 1.00 & 5.00 & 5.00 & 3.47 & 3.47 & 1.02 & 0.92 \\
\hline 15 & 12 & 12 & 1.00 & 1.00 & 5.00 & 5.00 & 3.45 & 3.46 & 1.18 & 0.99 \\
\hline 16 & 31 & 39 & 1.00 & 1.00 & 5.00 & 5.00 & 3.44 & 3.43 & 0.99 & 0.89 \\
\hline 17 & 10 & 25 & 1.00 & 1.00 & 5.00 & 5.00 & 3.44 & 3.43 & 1.16 & 1.07 \\
\hline 18 & 22 & 50 & 1.00 & 1.00 & 5.00 & 5.00 & 3.36 & 3.41 & 1.19 & 1.05 \\
\hline 19 & 13 & 38 & 1.00 & 1.00 & 5.00 & 5.00 & 3.32 & 3.40 & 1.08 & 0.83 \\
\hline 20 & 42 & 9 & 1.00 & 1.00 & 5.00 & 5.00 & 3.29 & 3.39 & 1.28 & 1.13 \\
\hline 21 & 19 & 3 & 1.00 & 1.00 & 5.00 & 5.00 & 3.27 & 3.39 & 1.20 & 1.06 \\
\hline 22 & 25 & 15 & 1.00 & 1.00 & 5.00 & 5.00 & 3.26 & 3.37 & 1.20 & 1.15 \\
\hline 23 & 39 & 41 & 1.00 & 1.00 & 5.00 & 5.00 & 3.21 & 3.30 & 1.14 & 0.98 \\
\hline 24 & 20 & 22 & 1.00 & 1.00 & 5.00 & 5.00 & 3.19 & 3.28 & 1.04 & 0.89 \\
\hline 25 & 11 & 19 & 1.00 & 1.00 & 5.00 & 5.00 & 3.19 & 3.28 & 1.30 & 0.96 \\
\hline 26 & 3 & 40 & 1.00 & 1.00 & 5.00 & 5.00 & 3.19 & 3.28 & 1.11 & 0.95 \\
\hline 27 & 38 & 8 & 1.00 & 1.00 & 5.00 & 5.00 & 3.18 & 3.27 & 1.11 & 0.90 \\
\hline 28 & 14 & 46 & 1.00 & 1.00 & 5.00 & 5.00 & 3.18 & 3.23 & 1.22 & 0.98 \\
\hline 29 & 40 & 13 & 1.00 & 1.00 & 5.00 & 5.00 & 3.14 & 3.23 & 1.23 & 1.01 \\
\hline 30 & 36 & 48 & 1.00 & 1.00 & 5.00 & 5.00 & 3.09 & 3.20 & 1.11 & 1.08 \\
\hline 31 & 26 & 37 & 1.00 & 1.00 & 5.00 & 5.00 & 3.08 & 3.18 & 1.29 & 0.91 \\
\hline 32 & 28 & 11 & 1.00 & 1.00 & 5.00 & 5.00 & 3.08 & 3.15 & 1.30 & 1.14 \\
\hline 33 & 49 & 20 & 1.00 & 1.00 & 5.00 & 5.00 & 3.06 & 3.13 & 1.15 & 0.94 \\
\hline 34 & 7 & 7 & 1.00 & 1.00 & 5.00 & 5.00 & 3.06 & 3.10 & 1.29 & 1.01 \\
\hline 35 & 2 & 36 & 1.00 & 1.00 & 5.00 & 5.00 & 3.05 & 3.07 & 1.12 & 0.95 \\
\hline 36 & 46 & 28 & 1.00 & 1.00 & 5.00 & 5.00 & 3.03 & 3.04 & 1.19 & 1.13 \\
\hline 37 & 9 & 49 & 1.00 & 1.00 & 5.00 & 5.00 & 3.01 & 3.02 & 1.34 & 0.94 \\
\hline 38 & 37 & 14 & 1.00 & 1.00 & 5.00 & 5.00 & 2.97 & 3.01 & 1.16 & 1.05 \\
\hline 39 & 41 & 23 & 1.00 & 1.00 & 5.00 & 5.00 & 2.97 & 2.98 & 1.35 & 0.98 \\
\hline 40 & 18 & 2 & 1.00 & 1.00 & 5.00 & 5.00 & 2.90 & 2.80 & 1.30 & 0.96 \\
\hline 41 & 8 & 26 & 1.00 & 1.00 & 5.00 & 5.00 & 2.88 & 2.75 & 1.26 & 1.20 \\
\hline 42 & 23 & 44 & 1.00 & 1.00 & 5.00 & 5.00 & 2.86 & 2.74 & 1.22 & 1.10 \\
\hline 43 & 35 & 35 & 1.00 & 1.00 & 5.00 & 5.00 & 2.84 & 2.73 & 1.19 & 1.08 \\
\hline 44 & 44 & 47 & 1.00 & 1.00 & 5.00 & 5.00 & 2.75 & 2.70 & 1.27 & 0.99 \\
\hline 45 & 16 & 17 & 1.00 & 1.00 & 5.00 & 5.00 & 2.73 & 2.64 & 1.33 & 1.01 \\
\hline 46 & 6 & 34 & 1.00 & 1.00 & 5.00 & 5.00 & 2.70 & 2.62 & 1.41 & 0.93 \\
\hline 47 & 47 & 18 & 1.00 & 1.00 & 5.00 & 5.00 & 2.68 & 2.61 & 1.22 & 1.04 \\
\hline 48 & 17 & 6 & 1.00 & 1.00 & 5.00 & 5.00 & 2.65 & 2.57 & 1.33 & 1.03 \\
\hline 49 & 34 & 16 & 1.00 & 1.00 & 5.00 & 5.00 & 2.51 & 2.51 & 1.18 & 0.95 \\
\hline 50 & 43 & 43 & 1.00 & 1.00 & 5.00 & 5.00 & 2.00 & 2.16 & 1.27 & 1.04 \\
\hline
\end{tabular}

Although the strategic patterns between the genders were in general different, Table 7 further shows only two statistically significant differences between females and males with Strategy $9(\mathrm{t}(197)=-210, \mathrm{p}=.037)$ and Strategy $41(t(197)=-1.99, p=.048)$. No significant differences were found with other strategies. This means that in terms of frequency levels, both genders made similarly frequent use of almost all the SILL strategies, except for Strategies 9 and 41. 
Table 7. Significant variance in individual strategies by gender

\begin{tabular}{lllllllll}
\hline Strategy & Gender & $\mathrm{N}$ & Mean & $S D$ & $S E$ & $d f$ & $t$ & $p$ \\
\hline 9 & $\mathrm{M}$ & 77 & 3.01 & 1.34 & .18 & 197 & -2.10 & .037 \\
& $\mathrm{~F}$ & 122 & 3.39 & 1.13 & & & & \\
4 & $\mathrm{M}$ & 77 & 2.97 & 1.35 & .17 & 197 & -1.99 & .048 \\
& $\mathrm{~F}$ & 122 & 3.30 & .98 & & & & \\
\hline
\end{tabular}

\section{Discussion}

This study conducted a survey on today's university students, aimed at exploring their use of LLS by means of the SILL (Oxford, 1990). A total of 199 valid surveys was collected. Both descriptive and inferential statistics were used for analytical purposes. The results show, first, that today's participants generally used most of the strategies described in the SILL. Additionally, they used some categories of SILL strategy more often than others. This strategic pattern is listed according to the rank order of the frequency of use by the participants as compensation strategies, metacognitive strategies, social strategies, memory strategies, cognitive strategies, and affective strategies. Furthermore, male and females had slightly different strategic patterns for learning English. That is to say, while they both used compensation strategies most frequently and affective strategies least, the males preferred social and metacognitive strategies to cognitive and memory strategies, but females preferred metacognitive and memory strategies to social and cognitive strategies. Despite some differences, no statistically significant variance between the genders was found at all in any of the SILL categories. Only a closer look at the differences between individual SILL items reveals that females used Strategies 9 and 41 statistically more frequently than males did. The mixed findings merit further discussion.

First, it is interesting to compare the overall results of this study with those of Green and Oxford (1995). To start with, both this study and theirs report the overall means for the six SILL categories as lying roughly between 2.90 and 3.40 or 3.50 . This means that today's language learners and those in the past both employed various strategies to help them to learn English. However, the students in these two studies developed different strategic patterns. Green and Oxford's participants reported themselves using the metacognitive SILL category most often and then the social, affective, cognitive, and memory categories down to the least often used, compensation. However, the current study's sample used the categories in the order of compensation most, through metacognitive, social, memory, cognitive, down to affective. Although metacognitive strategies were frequently used by the participants of both studies, today's language learners in Taiwan tend to favor compensation strategies a great deal more than those in Green and Oxford's study, whose use of compensation was the lowest of all the six categories. Another overt difference was noted in the use of affective strategies. Green and Oxford's sample reported their students frequently adopting the use of the affective strategy, but those of the current study reported the least use. The differences may be explained by the fact that the language learners in the two studies were of different cultures and education backgrounds. However, the difference may also serve as evidence supporting the view that today's English language learners in Taiwan have developed strategic patterns unlike those of the past. To ascertain this, it would be particularly helpful to compare the findings of this study to those of another study conducted also in Taiwan.

Interestingly, in the specific context of Taiwan, the results are only partially in line with the findings of Yeh (2010), who also investigated the SILL strategic patterns of Taiwanese university students. To begin with, the current study and Yeh's study both found that compensation strategies were the most popular SILL category among Taiwanese students. On the one hand, this may suggest that Taiwanese students probably deem compensation strategies the most effective ones to help them learn English. On the other, the results may also indicate that these strategies were effective in enabling Taiwanese learners of English to make up for missing knowledge when they used it. This is because the SILL compensation strategies are mostly associated with using different methods to guess the meanings of English words in different contexts (e.g., speaking and reading). Second, the students of this study and those of Yeh also ranked social strategies, memory strategies, and cognitive strategies in roughly the same places; that is, at around third, fourth, and fifth place, with mean scores roughly centering on 3.00. To some extent, this also confirms that Taiwanese students do employ particular strategies to help develop their English skills, rather than employing all or none.

The only two major differences between this study and Yeh's are in the categories of metacognitive and affective strategies: the former reports students using the metacognitive (2nd in ranking) a good deal more frequently than the affective (in the lowest rank) and the latter reporting completely the reverse. This specific difference may further suggest that today's Taiwanese students have indeed developed different strategic patterns than those in 
the past (at least a decade before). This difference may be attributed to the drastic change of the whole learning environment since then. The metacognitive strategies raise such questions as whether the respondents would outsource the following methods to improve their English: paying attention to other speakers of English, seeking methods to improve themselves, finding suitable persons to practice English with, and setting goals and timetables to improve their English. In comparison, today's language learners surely benefited much more from today's advanced modern learning facilities and rich resources. This is endorsed by the fact that today's language learners capitalize on modern technologies and media and are given more chances to interact with others (cf., Meyers, Erickson, \& Small, 2013; Haythornthwaite et al., 2016). Likewise, today's English learners in Taiwan have much more chance of being exposed to English in general and are also likely have more experience of learning with the communicative approach. Therefore, it seems reasonable that the affective strategies have taken a back seat now, since the strategies in this category mainly concerned the way in which learners coped with their negative feelings about learning English, such as the way they calmed themselves if they grew fearful of using English or making mistakes, tackled their nervous feelings when called upon to speak English, or discussed how they felt when they had to use English. Anxiety in speaking a foreign language does still exist in modern learning contexts. However, the phenomena described in earlier studies of the SILL may have lost something of their threat, since most current learners adopt the communicative approach in which anxieties about speaking are likely to be very much less than those in the past felt by students who had learned with a teacher-centered, deductive approach.

Furthermore, although this study and Green and Oxford's (1995) both report males and females using different strategic patterns, the findings in this study are very different from Green and Oxford's (1995) in that here almost no statistically significant differences were found between genders in their use of SILL items. Green and Oxford's female participants used most of the strategies as statistically significantly as the males did. However, in the present study, statistical variance was found with only two individual strategies: 9 and 41. Perhaps this means that today's learning context (hardware, software, and teaching approaches) has advanced to the point where it can better accommodate the language learning needs of today's male and female learners than it could in the past, thus allowing both genders to use similar strategies.

\section{Limitations and Suggestions for Future Studies}

This study tends to conclude that today's university EFL learners in Taiwan have indeed developed strategic patterns unlike those in the past. The possible reasons, as conjectured above, may involve changes in the advanced applications and teaching methods used in Taiwan. But, while the findings have justified the decision to revisit the use of LLS by university students and made contribution to the field, the research design has limitations that await future research to transcend.

First, while the sample size was enough to successfully substantiate a survey such as this one, in this study more females were involved than males. Although the total numbers of participants may also be considered sufficient for surveys in themselves, rigorous researchers may consider that a roughly equal distribution of genders would strengthen the survey result. Likewise, this study has considered only participants from one university in the northern part of Taiwan. Representativeness of the whole population of Taiwanese university students cannot be guaranteed.

In addition, this study examined only students' strategic patterns of LLS and differences between genders, but did not take account of their levels of language proficiency. Considering this in future studies is particularly important since many scholars in the field have demonstrated the significant positive correlations between language learners' proficiency levels and the use of LLS (Rao, 2016; Cáceres-Lorenzo, 2015) and identified that high achievers in a foreign language have different strategic patterns from low achievers (Ehrman \& Oxford, 1990; Green \& Oxford, 1995; Lee, 2018; Magogwe \& Oliver, 2007). It would shed much light in the field to find how far the changes of strategic patterns are associated with current students' language proficiency levels.

Moreover, the present study was conducted in the assumption that the changes of use of LLS by today's language learners in Taiwan could be attributed to the current improvements in the overall learning conditions. While such a supposition seems highly probable, rigorous researchers may like to consider studying it further and complementing it with in-depth qualitative interviews of today's language learners. For example, interviews about students' learning experience would probably have much to say about modern teaching methods (such as the communicative approach assumed here) and their impact on students' strategic behaviors. Inquiries into the specific learning resources or materials that today's language learners use might also tell us whether advanced applications nowadays have indeed contributed to the changes in their use LLS.

Finally, although this study adopted a popular and valid questionnaire (i.e., the SILL) (Oxford, 1990), perhaps in 
some ways it cannot generate a precise or accurate reflection of the strategic behaviors among today's language learners. After all, the SILL was invented before the Internet, and many technology-based strategic behaviors, such as googling useful English learning material, self-studying by watching YouTube channels, or writing English blogs, have not been included in it. Adapting or creating a survey that could better report modern language learners' use of LLS is thus a fruitful line of inquiry for future studies.

\section{Conclusion}

While many experimental studies over the past decades have described the patterns of LLS by language learners in general, this study recognizes the need to revisit this issue as it touches on today's language learners in Taiwan, given the changes of the overall learning context nowadays. While some of the strategic patterns of today's learners are similar to those in the past, this study has successfully identified the LLS that are used differently today: affective strategies, metacognitive strategies, and compensation strategies. Future educators who are keen to improve modern language learners' language abilities by introducing them to helpful LLS may like to take into consideration the findings of this study to maximize both the effects of teaching LLS to students and their learning.

\section{Acknowledgments}

This article was written with funding support from Taiwan's Ministry of Science and Technology (MOST 107-2410-H-032-057).

\section{References}

Anam, S., \& Stracke, E. (2016). Language learning strategies of Indonesian primary school students: In relation to self-efficacy beliefs. System, 60, 1-10. https://doi.org/10.1016/j.system.2016.05.001

Cáceres-Lorenzo, M. (2015). Teenagers learning Chinese as a foreign language in a European Confucius institute: The relationship between language learner strategies and successful learning factors. Language Awareness, 24(3), 255-272. https://doi.org/10.1080/09658416.2015.1075544

Chang, Y. J. (2015). Being a Part of the Globalized World? Globalization, English, and World Membership from Students. English Teaching \& Learning, 39(1), 69-97.

Cohen, A. D., \& Griffiths, C. (2015). Revisiting LLS research 40 years later. TESOL Quarterly, 49(2), 414-429. https://doi.org/10.1002/tesq.225

Cohen, A. D., Weaver, S. J., \& Li, T.-Y. (1998). The impact of strategies-based instruction on speaking a foreign language. In A. D. Cohen (Ed.), Strategies in learning and using a second language (pp. 107-156). London: Longman.

Ehrman, M., \& Oxford, R. (1990). Adult language learning styles and strategies in an intensive training setting. The Modern Language Journal, 74(3), 311-327. https://doi.org/10.1111/j.1540-4781.1990.tb01069.x

Freidman, T. (2005). The world is flat. New York: Farrar, Straus and Giroux.

Green, J. M., \& Oxford, R. (1995). A closer look at learning strategies, L2 proficiency, and gender. TESOL Quarterly, 29(2), 261-297. https://doi.org/10.2307/3587625

Gunning, P., \& Oxford, R. L. (2014). Children's learning strategy use and the effects of strategy instruction on success in learning ESL in Canada. System, 43, 82-100. https://doi.org/10.1016/j.system.2013.12.012

Haythornthwaite, C., Andrews, R., Fransman, J., \& Meyers, E. M. (Eds.). (2016). The Sage handbook of e-learning research. London: Sage. https://doi.org/10.4135/9781473955011

Hsiao, T., \& Oxford, R. (2002). Comparing theories of language learning strategies: A confirmatory factor analysis. The Modern Language Journal, 86, 368-383. https://doi.org/10.1111/1540-4781.00155

Khodadad, M., \& Kaur, J. (2019). The relation of language learning strategy uses with self-efficacy, motivation, and English language achievement. Journal of Modern Languages, 28, 1-19.

Lan, R., \& Oxford, R. L. (2003). Language learning strategy profiles of elementary school students in Taiwan. IRAL, 4l(4), 339-380. https://doi.org/10.1515/iral.2003.016

Lee, H. C. (2011). In defense of concordancing: An application of data-driven learning in Taiwan. Procedia-Social and Behavioral Sciences, 12, 399-408. https://doi.org/10.1016/j.sbspro.2011.02.049

Lee, J.-Y. (2018). The use of test-taking strategies and students' performances in answering TOEIC reading comprehension questions. Taiwan Journal of TESOL, 15(2), 33-64. 
Lee, J.-Y. (in press). Pedagogical effects of teaching test-taking strategies to EFL college students. Reading in a Foreign Language, 31(2).

Lin, M. H., \& Lee, J.-Y. (2017). Pedagogical suitability of data-driven learning in EFL grammar classes: A case study of Taiwanese students. Language Teaching Research (Online First), 1-21. https://doi.org/10.1177/1362168817740899

Lin, M. H. (2016). Effects of corpus-aided language learning in the EFL grammar classroom: A case study of students' learning attitudes and teachers' perceptions in Taiwan. TESOL Quarterly, 50(4), 871-893. https://doi.org/10.1002/tesq.250

Magogwe, J. M., \& Oliver, R. (2007). The relationship between language learning strategies, proficiency, age and self-efficacy beliefs: A study of language learners in Botswana. System, 35(3), 338-352. https://doi.org/10.1016/j.system.2007.01.003

Meyers, E. M., Erickson, I., \& Small, R. V. (2013). Digital literacy and informal learning environments: an introduction. Learning, Media and Technology, 38(4), 355-367. https://doi.org/10.1080/17439884.2013.783597

Mizumoto, A., \& Takeuchi, O. (2009). Examining the effectiveness of explicit instruction of vocabulary learning strategies with Japanese EFL university students. Language Teaching Research, 13(4), 425-449. https://doi.org/10.1177/1362168809341511

Ngo, N. (2019). Understanding the impact of listening strategy instruction on listening strategy use from a socio-cultural perspective. System, 81, 63-77. https://doi.org/10.1016/j.system.2019.01.002

Nguyen, L. T. C., \& Gu, Y. (2013). Strategy-based instruction: A learner-focused approach to developing learner autonomy. Language Teaching Research, 17(1), 9-30. https://doi.org/10.1177/1362168812457528

Oxford, R. L. (1990). Language learning strategies: What every teacher should know. Boston: Heinle.

Oxford, R. L. (2017). Teaching and researching language learning strategies: Self-regulation in context (2nd ed.). New York: Routledge. https://doi.org/10.1080/17501229.2017.1317262

Oxford, R. L., \& Burry-Stock, J. A. (1995). Assessing the use of language learning strategies worldwide with the ESL/EFL version of the Strategy Inventory for Language Learning (SILL). System, 23(1), 1-23. https://doi.org/10.1016/0346-251X(94)00047-A

Papadopoulou, I., Kantaridou, Z., Platsidou, M., \& Gavriilidou, Z. (2018). The SILL revisited in light of the S2R model of language learning. The Language Learning Journal, 46(5), 544-556. https://doi.org/10.1080/09571736.2018.1502739

Rahman, M. M., \& Pandian, A. (2018). A critical investigation of English language teaching in Bangladesh: Unfulfilled expectations after two decades of communicative language teaching. English Today, 34(3), 4349. https://doi.org/10.1017/S026607841700061X

Rao, Z. (2007). Training in brainstorming and developing writing skills. ELT Journal, 61(2), 100-106. https://doi.org/10.1093/elt/ccm002

Rao, Z. (2016). Language learning strategies and English proficiency: Interpretations from information-processing theory. The Language Learning Journal, 44(1), 90-106. https://doi.org/10.1080/09571736.2012.733886

Rose, H., Briggs, J. G., Boggs, J. A., Sergio, L., \& Ivanova-Slavianskaia, N. (2018). A systematic review of language learner strategy research in the face of self-regulation. System, 72, 151-163. https://doi.org/10.1016/j.system.2017.12.002

Saks, K., \& Leijen, Ä. (2018). Adapting the SILL to measure Estonian learners' language learning strategies: the development of an alternative model. The Language Learning Journal, 46(5), 634-646. https://doi.org/10.1080/09571736.2016.1191169

Shin, H. W., \& So, Y. (2018). The moderating role of socioeconomic status on motivation of adolescents' foreign language learning strategy use. System, 73, 71-79. https://doi.org/10.1016/j.system.2017.11.007

Tan, K. E., Ng, M. L. Y., \& Saw, K. G. (2010). Online activities and writing practices of urban Malaysian adolescents. System, 38(4), 548-559. https://doi.org/10.1016/j.system.2010.09.014

Wright, J., Ahn, Y. H., \& Lee, K. (2018). Investigating language learning strategies in English conversation using non-hierarchical cluster analysis. English Teaching, 73(1), 183-200. 
Wu, M. L., \& Tu, C. T. (2009). SPSS \& the Application and Analysis of Statistics (2nd ed.). Taipei: Wu Nan.

Yang, M. N. (2007). Language learning strategies for junior college students in Taiwan: Investigating ethnicity and proficiency. Asian EFL Journal, 9(2), 35-57.

Yang, N. D. (1992). Second language learners' beliefs about language learning and their use of learning strategies: A study of college students of English in Taiwan. Unpublished doctoral dissertation, the University of Texas at Austin, USA.

Yang, N. D. (1999). The relationship between EFL learners' beliefs and learning strategy use. System, 27(4), 515-535. https://doi.org/10.1016/S0346-251X(99)00048-2

Yang, W. (2017). From similarity to diversity: The changing use of language learning strategies in content and language integrated learning at the tertiary level in Taiwan. English Teaching \& Learning, 41(1), 1-32.

Yeh, M. H. (2010). The case study of language learning strategies used by vocational college foreign language-majored students in Taiwan: Using TSINT students as example. Northern Taiwan Journal, 33, 195-207.

\section{Copyrights}

Copyright for this article is retained by the author, with first publication rights granted to the journal.

This is an open-access article distributed under the terms and conditions of the Creative Commons Attribution license (http://creativecommons.org/licenses/by/4.0/). 